First draft of:

Hamid Taieb, "Brentano on Properties and Relations", in Uriah Kriegel (ed.), Routledge Handbook of Franz Brentano and the Brentano School, Routledge, London 2017.

Please quote from the published version.

\title{
Brentano on Properties and Relations
}

\author{
Hamid Taieb ${ }^{1}$
}

Brentano wrote his doctoral dissertation on Aristotle's ontology (Brentano 1862/1975a). However, the books and articles that Brentano published during his lifetime do not contain much information about his own theory of properties and relations. His main texts on this topic can be found in the posthumous volumes The True and the Evident (Brentano 1930/1966b), The Theory of Categories (1933/1981a), and The Renunciation of the Unreal (1966a), which mainly contain documents from after his reistic turn of 1904 (on reism, see Chap. 16). The manuscripts "About the Theory of Categories" (Brentano 1992-1993), "On Substance" (1993), and "Abstraction and Relation" (2013a/c), all from approximately 1900, are Brentano's most important published pre-reistic texts on properties and relations. Some information is also present in Brentano's logic lectures, given from 1869-1870 until 1877 in Würzburg and Vienna (Brentano 2011). ${ }^{2}$ Much information on the young Brentano's theory of properties and relations can be found in the metaphysics lectures given in Würzburg from 1867 onwards (ms. M 96), but these lectures are unpublished.

In this chapter, I will focus on Brentano's theory of properties and relations as established during his mature period, from Psychology from an Empirical Standpoint onwards, published in 1874, until his death, in 1917, and indicate the most important changes that his reistic turn entailed for his theory of properties and relations. ${ }^{3}$ First, I discuss the ontological features common to properties and relations. Second, I deal with relations in particular.

\footnotetext{
${ }^{1}$ I thank Nicole Osborne for having checked my English.

2 For the dating of these lectures, see Rollinger 2011.

3 I will briefly outline the young Brentano's theory of properties and relations in the footnotes. For the recognition of three periods in Brentano's ontology, namely "conceptualism" (1862-1874), "ontology of intentionality" (1874-1904), and "reism" (19041917), see Chrudzimski 2004, Chrudzimski, Smith 2004.
} 


\section{Ontological features common to properties and relations}

Abstract names, for Brentano, designate either "metaphysical parts" or "logical parts" (Brentano 2011: 86). "Metaphysical parts" are particular properties and relations, either essential or accidental, of a given concrete particular or "metaphysical whole". "Logical parts" are the "general marks" composing the definition, or "logical whole", of an individual of a given genus. Thus, "redness" can either designate the particular redness of a given red thing or the species 'redness' composing the definition of this particular redness. ${ }^{4}$

Metaphysical wholes and parts, or concrete and abstract particulars, are correlatives: a red thing is red through redness, and redness is the redness of a red thing (Brentano 2013a/c: 466-467/439-440). Both concrete and abstract particulars exist. However, they do not have the same ontological status. Concrete particulars are "real", whereas abstract particulars are "unreal" (not to be confused with "nonexistent") (Brentano 2013a/c: 472/438). The distinction between realia-real beings, also called "subsistent" (wesenhaft)—and irrealia-unreal beings, also called "non-subsistent" (unwesenhaft)—is based on causality:

There is being that begins without itself being caused, [but the beginning of which] is simply due to the fact that something else is caused. Likewise it ceases to be without itself undergoing a destructive influence or being deprived of a sustaining influence. It begins, persists, and ceases to be en parergo, so to speak. [...] Such being we call "non-subsistent". Something subsistent, by contrast, is that which as such can and does causally bring something about, and which as such cannot begin without being causally brought about and cannot as such cease to be without as such undergoing a [destructive] influence or removal of a sustaining influence. (Brentano 2013a/c: 466$-467 / 432-433$, translation slightly modified)

Thus, concrete particulars are causally efficacious and sensible and have a proper generation and corruption, whereas abstract particulars, as Chrudzimski says, are not, as such, "integrated into the causal network of the world". Yet both concrete and abstract particulars exist (see Chrudzimski 2004: 138-141 for a detailed analysis of these passages from Brentano 2013a).

According to Chrudzimski and Smith, Brentano is a trope theorist, i.e. he only admits abstract particulars in his ontology, not abstract universals. In other words, of the two kinds of parts that abstract names designate, namely "metaphysical" and "logical

\footnotetext{
${ }^{4}$ The most detailed discussion of the notions of metaphysical and logical parts is not found in Brentano 2011, but in Brentano's Würzburgian metaphysics lectures, presented in Baumgartner, Simons 1992-1993: 60-62, Chrudzimski 2004: 95-110, Chrudzimski, Smith 2004: 202-204, and Baumgartner 2013: 232-236, which I follow here.
} 
parts", only the first one would find a place in Brentano's ontology (Chrudzimski 2004, Chrudzimski, Smith 2004). It is true that Brentano is not a friend of universals. He rejects both "Platonic", or "transcendent", and "Aristotelian", or "immanent", realism of universals: general entities exist neither in a "world of Ideas" nor in things themselves. ${ }^{5}$ Thus, certainly the only abstracta that Brentano wants to admit in his ontology are abstract particulars. However, as I shall show, the reader, in view of some specific texts, could have worries about Brentano's theory of individuation and think that some of his properties and relations are disguised universals. ${ }^{6}$

Contemporary philosophers think that tropes must be simple, i.e. that their qualitative and individuating features should not be ontologically distinct. Indeed, if tropes were entities with two distinct "ontological grounds", providing them with quality and individuality respectively, they would become complex entities constituted by a universal and a "substrate" or individuator: the individuator would be extrinsic to the quality, which, thus, would be a universal, and the particular would be the complex entity made of the universal and the individuator (Maurin 2002: 11-21; see also Campbell 1990: 56-57). As Moreland (2001: 59) writes:

The trope view must assay a basic trope as a simple in order to avoid assigning the individuating and qualitative roles to non-identical constituents in the qualityinstance, for this is what realists do (e.g. $\operatorname{red}_{1}$ has an individuator, say, a bare particular expressed by 1 , the universal redness, and a tie of predication).

For example, someone who thinks that tropes are individuated through their "spatiotemporal position" does not mean "that place and the quality present at that place are distinct beings, one the particularizer and the other a universal, but that 'quality-at-a-place' is itself a single, particular, reality" (Campbell 1981: 483; see also Moreland 2001: 54, Maurin 2002: 18).

What about Brentano? According to him, accidents are individuated by the substance of the concrete particular of which they are the parts (Brentano 1992-1993: 263, 267-268, 1993: 30-34). For physical accidents, this substance is the body, and for psychic accidents it is the self:

\footnotetext{
${ }^{5}$ See notably Brentano 2011: 34, 38-39, 1930/1966b: 74/43. For the distinction between "Platonic" and "Aristotelian" realism of universals, see Armstrong 1978. One could wonder whether "Aristotelian realism" was actually defended by Aristotle. At any rate, Brentano was not attributing immanent realism to Aristotle, but to William of Champeaux, a philosopher of the $12^{\text {th }}$ century (see notably Brentano 1966a: 317). On immanent realism in the history of philosophy, see Erismann 2011.

${ }^{6}$ Chrudzimski 2004: 140 n. 133 evokes such an hypothesis on the basis of Brentano 2013 a/c: 472/438, but finally rejects it, and maintains that Brentano's properties and relations are tropes. In my opinion, the "disguised universals" hypothesis is rooted in, and confirmed by Brentano 1992-1993 and 1993.
} 
Specifically similar acts are individually distinct when they are mine or someone else's. The individualizer is the subject. (Brentano 1993: 33; my translation)

Thus, Brentano's particular accidents have ontologically-distinct qualitative and individuating grounds. Regarding the body, it is a combination of a series of abstract qualitative properties and an abstract spatial localization property (see Brentano 1992-1993: 259-264, 1993: 30, 34 and Chrudzimski 2004: 145-146). The body's qualitative properties and its spatial localization property mutually individuate themselves. More precisely: two things "of such quality" are individuated by their simultaneous differences of localization, whereas two things successively "at such a place" are individuated by their qualitative differences (Brentano 1993: 259-261, 2013a/c: 471-472/437-438; see also the later Brentano 1911c: 59 n. 1). Again, there is a distinction between the properties of the body and their individuators, which are also properties. Yet this distinction is probably only conceptual. Indeed, according to Brentano, although the colour and the spatial localization of a given spot in the perceptual field fall under distinct "genus" or concepts, they "penetrate one another" ontologically (Brentano 1982/1995b: 14-20/17-22 and Chap. 17). Generalizing this thesis, one could say that, for Brentano, the body's qualitative properties and its spatial localization are only conceptually distinct, i.e. that bodies are constituted by simple "qualities-at-a-place", or simple "qualified-spatial-localizations". Regarding the self, Brentano, in his Psychology, says that it is a "unified whole" constituted by mental acts, which are abstract entities (Brentano 1874/1973a: b. II, Ch. IV and Mulligan 2004: 86-88). Later, he affirms that the self is a "part" of consciousness, more precisely a "metaphysical part", i.e. apparently an abstract entity. The self seems to be simple (i.e. without ontologically-distinct qualitative and individuation grounds) and primitively individuated (see Brentano 1993: 35, and Chap. 15; on primitive individuation of tropes, see Maurin 2014). Thus, the body's properties and the self, for Brentano, seem to be genuine tropes, whereas his particular accidents have ontologically-distinct qualitative and individuation grounds, and resemble complex entities constituted by a universal and an individuator. Apparently, Brentano and his pupils saw the problem. During his reistic period, Brentano says that one would be wrong to think that:

many individual things correspond [to a general concept], but such that they are parts of another individual thing and receive their individuation from outside through their connection with this thing and its other parts. (Brentano 1933/1981a: 60-61/52-53, unfaithful to ms. M 70, ${ }^{\circ} 30837$; translation modified on the basis of the manuscript ${ }^{7}$ )

${ }^{7}$ As I learned from Guillaume Fréchette (directly) and Robin Rollinger (indirectly), Kastil took some liberties in editing Brentano 1933. Indeed, the passage that I quote here is not faithful to the manuscript, which I follow. 
And Kastil adds that such extrinsically individuated parts are "a special kind of intermediate thing falling between the absurd universal things and the real individual things". ${ }^{8}$

After his reistic turn, Brentano rejects the existence of abstracta: only things exist, i.e. concrete particulars. Redness as such, i.e. as abstract, does not exist, but is a mere "fiction"; only something red exists (Brentano 1933/1981a: 6-7/17). Concrete particulars are either substances or accidents. Accidents are not abstract parts, but concrete wholes, with a substance as a part (Brentano 1933/1981a: 11/19). They are individuated by their substances. Bodies are no longer substances, but qualitative accidents, individuated by the spatiotemporally-localized, individual substance that they contain. Souls are concrete, individual substances (see notably Brentano 1933/1981a: 246-248/177-178 and Kastil 1933/1981: 363-364 n. 1/253-254 n. 297). ${ }^{9}$ What about individuation of accidents? As wholes, Brentano's accidents are no longer individuated "extrinsically", but intrinsically, since their individuator, the substance, is a part of them. However, they still have ontologically-distinct qualitative and individuation grounds: a non-substantial, qualitative portion ${ }^{10}$ and an individuating substance. Thus, one could wonder whether these qualitative portions as such are individual. ${ }^{11}$

\footnotetext{
${ }^{8}$ This remark, in Brentano 1933/1981a: 60-61/52-53, is probably Kastil's own, since it is missing in the manuscript (ms. M 70, $\mathrm{n}^{\circ} 30837$ ).

${ }^{9}$ Since Brentano, in his Würzburgian metaphysic lectures, rejects the existence of abstracta, considering them simply "fictions", his early position resembles his reistic theory (see Chrudzimski 2004, Baumgartner 2013: 236, Kriegel forthcoming: 1-2 n. 1).

${ }^{10}$ Brentano strangely affirms that an accident is a whole having no other "part" than its substance (see Chap. 17). This said, it is clear that (in one sense or another) 'something more' than the substance constitutes the accident. It is this 'something more' that I call "qualitative portion".

${ }^{11}$ See also Simons 1988: 53-54 about the "lack of individuality" of Brentano's reistic accidents, as well as Chrudzimski 2004: 188.
} 


\section{Ontological features proper to relations}

Brentano, before his reistic turn, distinguishes relations, relata, and relatives. Relations are (allegedly) abstract particulars, e.g. this fatherhood and this childhood. Relata are particular bearers of relations, e.g. Sophroniscus and Socrates. Relatives are concrete particulars constituted by a relation and a relatum, e.g. this father and this son. It has been argued that Brentano's relations are monadic properties, since they depend on Aristotle's theory of relations or "pros ti", which would be monadic properties (Chrudzimski 2001: 194, Sauer 2006: 22). However, it is not clear that Aristotle's relations are monadic, since, at least in the standard cases, the existence of a relative entails the existence of a correlative: if a relation exists, then its own relatum, a converse relation, and the relatum of the converse relation exist (see Aristotle, Cat. VII, 6b28-8a12 and Hood 2004: 96). Moreover, for Brentano, the logical form of relations seems not to be $x(R y)$, where $(R y)$ would be a monadic predicate, but something closer to the polyadic Russellian logical form $x R y:{ }^{12}$

When I predicate "bigger than A" of something, I do not predicate A of it, but I relate it to A. (Brentano 1966a: 205; my translation)

Besides, one finds clear affirmation of the polyadic dimension of relational properties in Brentano's pre-reistic texts:

[Relative determinations] depend, for their individual subsistence, on the one of the absolute [determinations] (certainly also on the [subsistence] of another thing than the one to which they are ascribed), but the latter do not inversely [depend on the former]. (Brentano 1992-1993: 258-259; my translation, and my additions, except for "subsistence")

For Brentano, before reism, relatives are ontologically and conceptually dependent on one another. A relation can only exist and be thought with its own relatum, a converse relation, and the relatum of the converse relation (Brentano 2013a/c: 435436/469-470). Thus, unlike philosophers who consider converse relations to be a matter of mere "linguistic presentation" (Massin 2009: 580, Williamson 1985; see also Fine 2000), Brentano takes them seriously both conceptually and ontologically.

Following a medieval distinction, Brentano considers some relations to be real (relationes reales), whereas others are unreal (relationes rationis). ${ }^{13}$ A relation is real when its corresponding relative begins or ceases to exist by having itself been

12 On Russell's criticism of the logical form of "monadistic" relational predicates like (Ry), see Russell 1903: § 214.

13 On the medieval distinction between "real relations" and "relations of reason", see Henninger 1989. 
"causally brought about" or having itself undergone "a [destructive] influence or removal of a sustaining influence", whereas a relation is unreal when its corresponding relative begins or ceases to exist because something else has been generated or destroyed (Brentano 2013a/c: 466-467/432-433). For example, regarding "relations of comparison", 'something larger' or 'something smaller' begin or cease to exist not by themselves undergoing a causal influence, but because their own height or the height of their correlative has undergone such influence. Thus, both relations are unreal. Regarding "causal relations", 'something caused' obviously begins to exist by undergoing a causal effect itself, which is clearly not the case for 'something causing'. When an active thing brings about 'something caused', for example when the sun heats a stone, it becomes 'something causing' en passant. Thus, the effect is really related to the cause, but not the cause to the effect. Regarding the intentional relation, the thinking-thing is a real relative, whereas the thought-thing is an unreal relative. Indeed, the thought-thing is generated when the mental act is generated and disappears when the mental act disappears (Brentano 2013a/c: 470-471/436-437, 1982/1995b: 21/23-24). There is a major difference between these three examples of correlations: unreal relatives of comparison and unreal causal relatives have a real relatum as a part (two things with quantitative features for the relations of comparison, an active thing for the relation of the cause to the effect); in the case of the intentional correlation, the unreal correlate has an unreal relatum as a part, i.e. the thought-thing, as an "immanent object", depends on the act with respect to all its parts (see Chap. 4).

After his reistic turn, Brentano will abandon irrealia and, thus, unreal relatives. As a consequence, his correlations will be ontologically impoverished. In some cases, there is just one relative left, but with a relatum in front of it, e.g. causality: there is an effect left, i.e. a real relative containing a real relatum, and an active thing, i.e. a real relatum (Brentano 1976/1988: 125-126/75). In some cases, there is all in all only one relative left, e.g. intentionality: there is just the thinking subject left, a real relative containing a real relatum. Brentano will nevertheless remain a "realist" of relatives: indeed, relatives of comparison ontologically "coincide" with their underlying absolute features, but this does not hold for other relatives, e.g. intentional or causal ones, which are ontologically irreducible (Brentano 1933/1981a: 258-259/184-185, 1966a: 310-311). Initially, Brentano said that relatives without a term (i.e. without even a relatum in front of them) are merely conceptually relative. The direct (or "in recto") presentation of a thinking subject entails the concomitant indirect (or "in obliquo") presentation of the object toward which the subject is directed. Yet, from an ontological point of view, the thinking subject is not a relative proper, but something "relative-like" (Brentano 1911/1973a: Appendix I). However, Brentano changes his mind on this point around 1915-1916 and argues "isolated" relatives are genuine relatives: the thinking subject is genuinely relative even when its object is impossible; the "aftereffect" is genuinely 
relative even when its cause has disappeared (Brentano 1933/1981a: 237-238/171; see Gilson 1955: 138-154, Sauer 2006: 21-24, Taieb forthcoming). Thus, in nonreistic, abstract terms, Brentano admits in his ontology what Grossmann (1969: 3132) calls "abnormal relations", i.e. relations without an existent term. Certainly this is an abnormal thesis, and Brentano's death in 1917 unfortunately deprived it of an extensive justification. 


\section{Bibliography}

Armstrong D.M. (1978). Universals and Scientific Realism, vol. 1-2. Cambridge: Cambridge University Press.

Aristotle (1831). Opera, vol. I. Ed. E. Bekker. Berlin: Reimer.

Baumgartner W. (2013). “Franz Brentano’s Mereology”. In Fisette D., Fréchette G. (eds), Themes from Brentano.

Baumgartner W., Simons P. (1992-1993). "Brentanos Mereologie". Brentano Studien 4: 53-77.

Brentano F. (1992-1993). "Zur Kategorienlehre". Ed. M. Antonelli. Brentano Studien 4: 251-270.

- (2011). EL 80, “Logik”. Ed. R. Rollinger.

gams.uni-

graz.at/archive/objects/context:bag/methods/sdef:Context/get?mode=logik

- (1914). M 70, "Der Name Seiendes im eigentlichen und uneigentlichen Sinne". Franz Clemens Brentano Compositions (MS Ger 230), Houghton Library, Harvard University.

- (1867). M 96, “Ontologie (Metaphysik)”. Franz Clemens Brentano Compositions (MS Ger 230), Houghton Library, Harvard University.

Campbell K. (1981). "The Metaphysic of Abstract Particulars". Midwest Studies in Philosophy 6 (1): 477-488.

— (1990). Abstract Particulars. Oxford: Basil Blackwell.

Chrudzimski A. (2001). "Die Intentionalitätstheorie Anton Martys". Grazer Philosophische Studien 62: 175-214.

- (2004). Die Ontologie Franz Brentanos. Dordrecht: Kluwer Academic Publishers.

Chrudzimski A., Smith B. (2004). “Brentano's Ontology: from Conceptualism to Reism". In Jacquette D. (ed.), The Cambridge Companion to Franz Brentano.

Erismann Ch. (2011). L'homme commun. La genèse du réalisme ontologique durant le haut Moyen Âge. Paris: Vrin.

Fine K. (2000). “Neutral Relations”. The Philosophical Review 109 (1): 1-33.

Fisette D., Fréchette G. (eds) (2013). Themes from Brentano. Amsterdam: Rodopi. 
Gilson L. (1955). La psychologie descriptive selon Franz Brentano. Paris: Vrin.

Grossmann R. (1969). "Non-Existent Objects: Recent Work on Brentano and Meinong". American Philosophical Quarterly 6 (1): 17-32.

Henninger M. (1989). Relations. Medieval Theories 1250-1325. Oxford: Clarendon Press.

Hood P.M. (2004). Aristotle on the Category of Relation. Lanham, Maryland: University Press of America.

Jacquette D. (ed.) (2011). The Cambridge Companion to Franz Brentano. Cambridge: Cambridge University Press.

Kastil A. (1933). “Anmerkungen des Herausgebers”. In Brentano F., Kategorienlehre. Trans. R.M. Chisholm, N. Guterman. In Brentano F. (1981), The Theory of Categories.

Kriegel U. (forthcoming). “Thought and Thing: Brentano's Reism as Truthmaker Nominalism". Philosophy and Phenomenological Research.

Massin 0. (2009). “The Metaphysics of Forces”. dialectica 63 (4): 555-589.

Maurin A.-S. (2002). If Tropes. Dordrecht: Kluwer Academic Publishers.

- (2014, Fall). “Tropes”. In Zalta E.N. (ed.), The Stanford Encyclopedia of Philosophy. http://plato.stanford.edu/archives/fall2014/entries/tropes/

Moreland J.P. (2001). Universals. Chesham: Acumen Publishing.

Mulligan K. (2004). "Brentano on the Mind". In Jacquette D. (ed.), The Cambridge Companion to Franz Brentano.

Rollinger R. (2011). “Editor's Preface”. In Brentano F., EL 80, “Logik”.

Russell B. (1903). The Principles of Mathematics. Cambridge: Cambridge University Press.

Sauer W. (2006). "Die Einheit der Intentionalitätskonzeption bei Brentano". Grazer Philosophische Studien 73: 1-26.

Simons P. (1988). "Brentano's Theory of Categories: a Critical Appraisal”. Brentano Studien 1: 47-61. 
Taieb H. (forthcoming). "Relations and Intentionality in Brentano's Last Texts". Brentano Studien 13.

Williamson T. (1985). "Converse Relations”. The Philosophical Review 94 (2): 249262. 